\title{
A multi-objective improved teaching learning based optimization algorithm for time-cost trade-off problems
}

\author{
M.A. Eirgash*, T. Dede \\ Karadeniz Technical University, Civil Engineering Department, Trabzon, Turkey
}

\begin{abstract}
In this paper, a multi-objective optimization model based on modified adaptive weight approach and improved teaching-learning based optimization (MAWA-ITLBO) algorithm is proposed for the solution of time-cost trade-off problems. The MAWA-ITLBO algorithm is the improved version of basic MAWATLBO algorithm by adding the concept of number of teachers as well as adaptive teaching factor. The effects of these parameters in TLBO are investigated in order to demonstrate the variation of the Pareto front solution. Thereby, the performance of the MAWA-ITLBO is compared to the existing methods using a wellknown 18-activity benchmark problem. A 63-activity problem is also included in computational experiments to validate the efficiency of the proposed MAWA-ITLBO. The results obtained by using the MAWA-ITLBO are compared with those obtained by using the basic MAWA-TLBO, genetic algorithm (GA), and ant colony optimization (ACO) algorithms. The obtained results demonstrate that the utilized MAWA-ITLBO is able to provide a superior set of Pareto-front solutions than that of previously proposed models.
\end{abstract}

\section{Keywords}

Modified Adaptive Weight Approach (MAWA); Teaching-Learning-Based Optimization (TLBO); Adaptive Teaching Factor (ATF); Pareto Front (PF); Number of Teacher (NT)

Received: 07 September 2018; Accepted: 28 September 2018

ISSN: 2630-5771 (online) (C) 2018 Golden Light Publishing All rights reserved.

\section{Introduction}

Considering the competitive environment in all industries, construction management is getting to be noticeably essential for the parties. And both the client and contractor look for the best economical scheduling subjected to different parameters such as time, cost and other operational resources. Project scheduling calculations are based on CPM (Critical Path Method). Each activity has a normal duration and a forced duration. Completing an activity in its forced duration needs more direct cost and resources. On the other hand, it leads to decrease project's total duration and indirect costs. The balancing between time and cost of a project is known as time cost trade-off problems (TCTP) in the literature. Reviewing the literature it is found out that, the solution to TCTP problems has been a challenge to researchers for a long time. Despite the considerable variety of techniques developed in optimization research and other disciplines to deal with this problem. The complexities of its solution calls for alternative approaches such as weighted sum method and nondominating sorting approach have been used to solve the TCTP problems. Moreover, weighted sum method is one of the firstly used methods on solving the time-cost trade off problems.

\footnotetext{
Corresponding author

Email: azim.eirgash@gmail.com
} 
The weighted sum method (WSM) aggregates a set of objectives into a single objective by premultiplying each objective with a user-supplied weight [1]. Although the idea is simple, the challenge is determining what values of the weights to use. It depends on the importance of each objective in the context of the problem and also a scaling factor.

Gen and Cheng [2] adopted the Adaptive Weight Approach (AWA) in construction TCO (also referred to as the $\mathrm{GC}$ approach hereafter).This approach converts the multiobjective problem to a single-objective problem and then utilizing a single-objective optimization approach to find the satisfactory solution which is known as adaptive weighted approach (AWA). The GC approach overcomes the weakness of weights selection in the conventional sum method. Also, under the four conditions, the Modified Adaptive Weighted Approach (MAWA) is proposed by Zheng et al. [3] and the deficiencies associated with the previous approaches are likely to be minimized.

Numerous studies have focused on achieving the Pareto front for the discrete time-cost trade-off problems. Genetic algorithms [3-4]; and ant colony optimization [5-7] are among the metaheuristic solution procedures proposed for the Pareto front optimization of discrete time-cost trade-off problems.

In recent decades, various modern metaheuristic optimization methods including genetic algorithms, simulated annealing, particle swarm optimization, ant colony optimization, and shuffled frog leaping optimization have been applied for solving TCT problems. Thereby, in this study, TLBO algorithm is applied as an alternative for solving TCTP problems.

TLBO that was proposed by Rao et al [8] simulates the influence of a teacher on the output of learners in a class. It has emerged as one of the simple and efficient techniques for solving singleobjective benchmark problems and real life application problems in which it has been empirically shown to perform well on many optimization problems. The basic TLBO algorithm has been already modified by Rao and Patel [9] to improve its efficiency and applied it to the optimization of thermal systems by introducing the number of teachers and adaptive teaching factor. It is observed that the proposed sole MAWA-TLBO algorithm is not able to find out the optimum solutions for the 18-activity and a more complex 63-activity problems [10]. Thereby, in the present study, number of teacher and adaptive teaching factor on obtaining the Pareto-front solution is also adapted to further investigate the exploration capacity of the proposed algorithm.

\section{Time - Cost Trade-off Problem (TCTP)}

TCTP is a bi-objective problem and the balanced relationship between time and cost is called TCT Problem. During planning or in case of a delay, the project manager needs to balance the time and cost of a project to improve the overall efficiency. Therefore, TCTP is adapted to identify the set of time - cost alternatives that will provide the optimal schedule. The time of a project $\mathrm{T}$ can be calculated according to the following equation.

$\mathrm{T}=\sum_{i}^{k} t_{i}^{k} x_{i}^{k}$

where $n$ is the number of total activities of a project; $t_{i}^{k}$ is the duration of activity $i$ when performing the $k^{\text {th }}$ option; $x_{i}^{k}$ is index variable of activity $i$ when performing the $k^{\text {th }}$ option:

$\underset{x i}{k}=\left\{\begin{array}{cc}1, \text { when activity i performs the kth option } \\ 0, & \text { else } \\ & \text { and } \\ \sum_{i}^{k} \underset{x i}{k}=1\end{array}\right.$

The project duration $T$ is calculated by using the critical path method depending on the defined activity relationships for that project. The total cost of a project consists of two parts: direct cost and indirect cost. Direct cost is determined by the sum of direct costs of all activities within a project network. On the other hand, indirect cost depends heavily upon the project duration, i.e., the longer the duration, the higher the indirect cost. The total 
cost of a project can be calculated by the following equation:

$C=\sum_{i}^{k} D C_{i}^{k} x i^{k}+t_{i} x i c_{i}^{k}$

where $\mathrm{C}$ is the total cost of a project; $D C_{i}{ }_{i}$ is the direct cost of activity $i$ when performing the $k^{\text {th }}$ option; $x_{i}^{k}$ is index variable of activity $i$ when performing the $k^{\text {th }}$ option; $t_{\mathrm{i}}$ is the duration of activity $i ; i c_{i}{ }^{k}$ is the indirect cost rate of a project.

\section{Modified Adaptive Weight Approach (MAWA) in Multi-Objective Optimization}

Weighted approach is applied to transform a multiple objective optimization problem to the optimization problem having single objective. Modified adaptive weight approach (MAWA) proposed by Zheng et al. [11] is used in this study to solve the multiobjective problem. To identify adaptive weight for each objective, MAWA benefits the information from the existing set of solutions. For MAWA, the formulations are expressed through the following four conditions [11]:

1. For $Z_{t}^{\max } \neq Z_{t}^{\min }$ and $Z_{c}^{\max } \neq Z_{c}^{\min }$

$v_{c}=Z_{c}^{\min } / Z_{c}^{\max }-Z_{c}^{\min }$

$v_{t}=Z_{t}^{\min } / Z_{t}^{\max }-Z_{t}^{\min }$

$v=v_{t}+v_{c}$

$w t=v t / v$

$w c=v c / v$

2. For $Z_{t}^{\max }=Z_{t}^{\min }$ and $Z_{c}^{\max }=Z_{c}^{\min }$

$w_{t}=w_{c}=0.5$

3. For $Z_{t}^{\max }=Z_{t}^{\min } \quad$ and $Z_{c}{ }^{\max } \neq Z_{c}{ }^{\text {min }}$

$w_{t}=0.9$

$w_{c}=0.1$

4. For $Z_{t}^{\max } \neq Z_{t}^{\text {min }}$ and $Z_{c}^{\text {max }}=Z_{c}^{\text {min }}$

$w_{t}=0.1$

$w_{c}=0.9$

where $Z_{t}^{\max }$ and $Z_{t}^{\text {min }}$ are maximum and minimum values for the objective of project duration, respectively, in the current iteration. Similarly, $Z_{c}{ }^{\max }$ and $Z_{c}{ }^{\text {min }}$ are maximum and minimum values for the objective of total direct cost, respectively, in the current iteration. $v_{t}$ and $v_{c}$ are ratio between the minimum value and difference between maximum and minimum points for the objective project duration and total direct cost, respectively. $w_{c}$ is weight for the objective of total direct cost, and $w_{t}$ is weight for the objective of time. These weights adjust itself with adaptive manner. It means that their values changes depending on the performance of the current population. According to MAWA, the following equation is evaluated to assign fitness to each solution:

$f(x)=w_{t} \frac{Z_{t}-Z_{t}^{\min }+r}{Z_{t}^{\max }-Z_{t}^{\min }+r}+w_{c} \frac{Z_{c}-Z_{c}^{\min }+r}{Z_{c}^{\max }-Z_{c}^{\min }+r}$

where $x$ shows any candidate solution in the current generation; $f(x)$ is the fitness of that solution; $Z_{c}$ and $Z_{t}$ represent the total cost and the time of the $x$ th solution, respectively. $r$ is a small positive random number between 0 and $1 ; w_{c}$, and $w_{t}$ are the adaptive weights for cost and time. To avoid a case of $Z_{c}{ }^{\max }$ $=Z_{c}{ }^{\text {min }}$ or $Z_{t}^{\text {max }}=Z_{t}^{\text {min }}, r$ is added in Eq. (8), [11]. The flowchart of the process can be seen in Fig. 1.

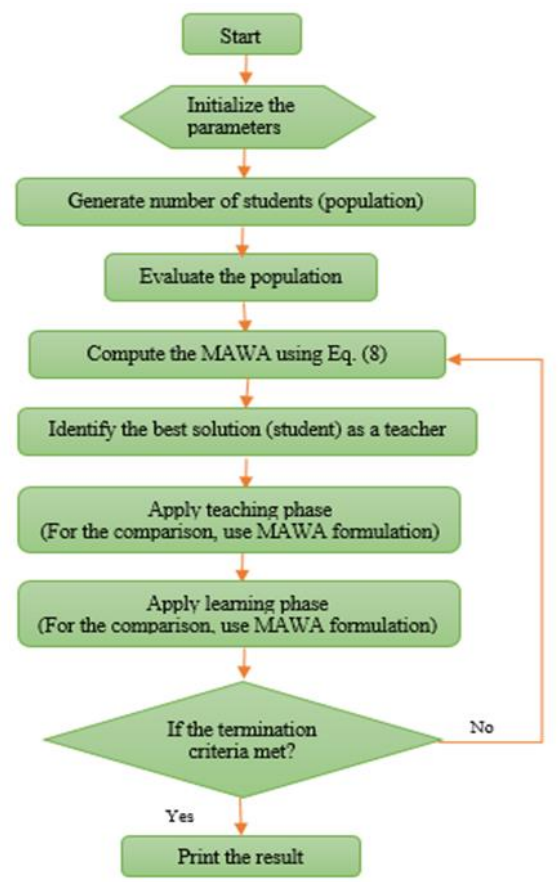

Fig 1. Flowchart of the MAWA-TLBO algorithm for TCTP 


\section{Multi-objective improved TLBO algorithm}

In the basic MAWA-TLBO algorithm, the output of the students is enhanced either by a teacher or by interaction among themselves. However, in the MAWA-ITLBO algorithm, this is done by introducing more than one teacher to the students. Furthermore, teaching factor is also improved to adaptive teaching factor.

\subsection{Number of teachers}

In the core TLBO, there is only one teacher, who teaches the students and struggles to raise their knowledge. This portion goes through the enhancement in TLBO by offering number of teachers (NT). In this system of learning, the whole class is isolated into various groups of students as per their levels, and the individual instructor is appointed to each gathering of students. In this way, every teacher attempts to enhance the information of appointed students. The Pseudo code of this modification is given below:

Initialize the population randomly and evaluate the same.

For $R N=1$ : Number of runs.

Rank the evaluated solutions (In ascending order for the minimization problem and in descending order for the maximization problem)

Select the best solution $f\left(X^{b}\right)$. This solution acts as the chief teacher $\left(T_{I}\right)$ of the class. Mathematically, $T_{l}=f\left(X^{b}\right)$ Select the other teachers $\left(T_{s}\right)$ based on the best solution (i.e. $\left.f\left(X^{b}\right)\right)$

$$
T_{s}=f\left(X^{b}\right) \pm r_{i} \times f\left(X^{b}\right) s=2,3, \ldots, N
$$

(Where, $r_{i}$ is the random number. If the value of the right side of the above equation is not equal to any of the values of the initially evaluated population then the value closer to that is selected from the initial population). Once, the teachers are identified, distribute the learners to the teachers based on their fitness value (i.e. result) as,

For $k=1$ to Population

If $T_{1} \leq f\left(X^{k}\right)<T_{2}$

Assign the learner $f\left(X^{k}\right)$ to teacher 1 (i.e $T_{1}$ )

Else If $T_{2} \leq f\left(X^{k}\right)<T_{3}$

Assign the learner $f\left(X^{k}\right)$ to teacher 2 (i.e $T_{2}$ )
Else If $T_{N-1} \leq f\left(X^{k}\right)<T_{N}$

Assign the learner $f\left(X^{k}\right)$ to

teacher $N$ - $I$ (i.e $\left.T_{N-1}\right)$

Else

Assign the learner $f\left(X^{k}\right)$ to

teacher $N$ - 1 (i.e $\left.T_{N-1}\right)$

Teacher phase

Learner phase

End For

\subsection{Adaptive teaching factor}

In TLBO, the teaching factor value (either one or two) is decided through heuristic step, which means that the learners acquire nothing or all the things taught by the teacher. However, in real practice, learners may learn in any proportion from the teacher. Therefore, teaching factor is improved to adaptive teaching factor (ATF). In the optimization algorithm a lower value of $T_{F}$ allows the finer search in small steps but causes slow convergence. A larger value of $T_{F}$ accelerates the search but it lowers the exploration capability. Considering this fact the teaching factor is modified as,

$$
\begin{array}{ll}
\left(T_{F}\right)_{s, i}=\left(\frac{f\left(X^{k}\right)}{T_{S}}\right) & \text { If } T_{S} \neq 0 \\
\left(T_{F}\right)_{1}=1 & \text { If } T_{S}=0
\end{array}
$$

where $f\left(X^{k}\right)$ is the result of any learner $k$ associated with group ' $s$ ' taking into account all the subjects at iteration $i$ and $T_{s}$ is the result of the teacher of the same group at the same iteration $i$. Therefore, teaching factor in ITLBO algorithm is the ratio of the result of the learner to the result of the teacher during an iteration. The teaching factor varies automatically during the search related to the result of the learner and the teacher. Thus, automatic tuning of $T_{F}$ improves the performance of the algorithm.

\section{Numerical examples}

To demonstrate the performance of the utilized MAWA-ITLBO model for obtaining Pareto front solutions of the TCTP, small and medium scale problems taken from the technical literature are investigated. The utilized algorithm was coded in 
MATLAB environment implemented on a personal computer having Intel (R) Core (TM) i3 CPU 2.40 $\mathrm{GHz}$ and 3GB RAM. Consecutive experimental run number is adopted as 10 for the entire instances.

\subsection{Empirical example of 18-activity project with five modes}

This 18-activity example problem was originally introduced by Feng et al. [4]. The network with logical relationship of FS is shown in Fig. 2. The model project includes five construction modes (options) for some activities, and the activity relationships are presented in Table 1 with corresponding construction time and cost values. The value of $\$ 1500 /$ day is adopted as indirect cost rate for the example.

Comparisons amongst the MAWA-ITLBO with the basic MAWA-TLBO [10], MAWA-GA [3], MAWA-AS [6] and MAWA- SGPU algorithms [7] are presented in Table 2 and Fig. 3 for this model project.

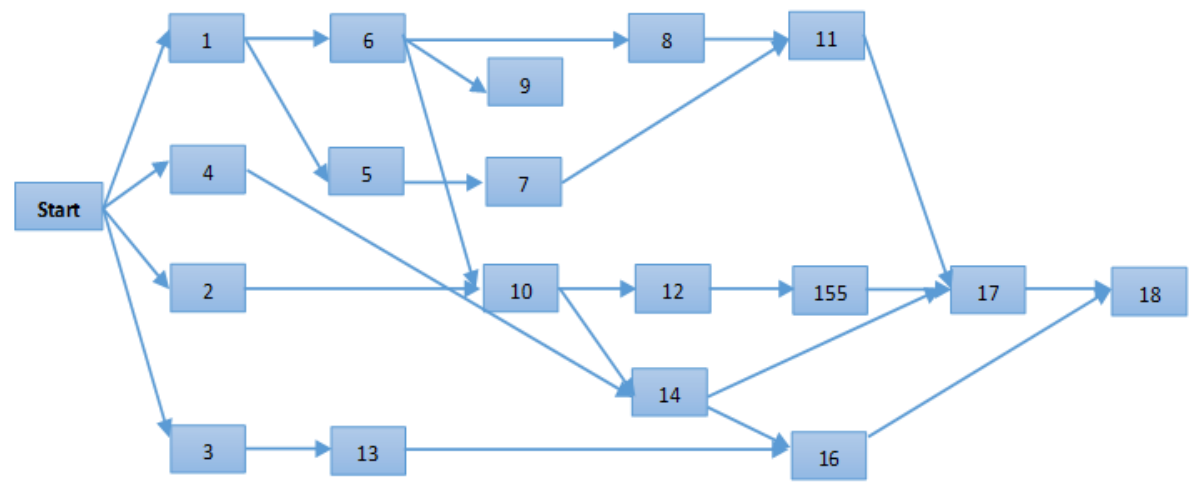

Fig. 2. Network configuration for the model project of 18 activities

Table 1. Options for 18-activities project with five modes

\begin{tabular}{|c|c|c|c|c|c|c|c|c|c|c|c|}
\hline \multirow[b]{2}{*}{$\begin{array}{l}\text { Activity } \\
\text { Number }\end{array}$} & \multirow[b]{2}{*}{$\begin{array}{c}\text { Precedent } \\
\text { Activity }\end{array}$} & \multicolumn{2}{|c|}{ Option /Mode1 } & \multicolumn{2}{|c|}{ Option /Mode2 } & \multicolumn{2}{|c|}{ Option /Mode3 } & \multicolumn{2}{|c|}{ Option /Mode4 } & \multicolumn{2}{|c|}{ Option /Mode5 } \\
\hline & & $\begin{array}{l}\text { Dur. } \\
\text { (day) }\end{array}$ & $\begin{array}{c}\text { Direct } \\
\text { Cost }(\$)\end{array}$ & $\begin{array}{l}\text { Dur. } \\
\text { (day) }\end{array}$ & $\begin{array}{c}\text { Direct } \\
\text { Cost }(\$)\end{array}$ & $\begin{array}{l}\text { Dur. } \\
\text { (day) }\end{array}$ & $\begin{array}{c}\text { Direct } \\
\text { Cost }(\$)\end{array}$ & $\begin{array}{l}\text { Dur. } \\
\text { (day) }\end{array}$ & $\begin{array}{c}\text { Direct } \\
\text { Cost }(\$)\end{array}$ & $\begin{array}{l}\text { Dur. } \\
\text { (day) }\end{array}$ & $\begin{array}{c}\text { Direct } \\
\text { Cost }(\$)\end{array}$ \\
\hline 1 & - & 14 & 2400 & 15 & 2150 & 16 & 2400 & 21 & 1500 & 24 & 1200 \\
\hline 2 & - & 15 & 300 & 18 & 2400 & 20 & 1900 & 23 & 1500 & 25 & 1000 \\
\hline 3 & - & 15 & 4500 & 22 & 4000 & 33 & 1800 & & & & \\
\hline 4 & - & 12 & 45000 & 16 & 35000 & 20 & 3200 & & & & \\
\hline 5 & 1 & 22 & 20000 & 24 & 17500 & 28 & 30000 & 30 & 10000 & & \\
\hline 6 & 1 & 14 & 40000 & 18 & 32000 & 24 & 15000 & & & & \\
\hline 7 & 5 & 9 & 30000 & 15 & 24000 & 18 & 18000 & & & & \\
\hline 8 & 6 & 14 & 220 & 15 & 21 & 16 & 22000 & 21 & & 24 & \\
\hline 9 & 6 & 15 & 300 & 18 & 240 & 20 & 200 & 23 & 208 & 25 & 120 \\
\hline 10 & 2,6 & 15 & 450 & 22 & 400 & 33 & 180 & & 150 & & 100 \\
\hline 11 & 7,8 & 12 & 450 & 16 & 350 & 20 & 320 & & & & \\
\hline 12 & $5,9,10$ & 22 & 2000 & 24 & 1750 & 28 & 1500 & 30 & & & \\
\hline 13 & 3 & 14 & 4000 & 18 & 3200 & 24 & 1800 & & & & \\
\hline 14 & 4,10 & 9 & 3000 & 15 & 2400 & 18 & 2200 & & & & \\
\hline 15 & 12 & 12 & 4500 & 16 & 3500 & & & & & & \\
\hline 16 & 13,14 & 20 & 3000 & 22 & 2000 & 24 & 1750 & 28 & 1500 & 30 & 1000 \\
\hline 17 & $11,14,15$ & 14 & 4000 & 18 & 3200 & 24 & 1800 & & & & 1200 \\
\hline 18 & 16,17 & 9 & 3000 & 15 & 2400 & 18 & 2200 & & & & 1000 \\
\hline
\end{tabular}


Table 2. Comparison between different algorithms of 18 -activity project with five modes

\begin{tabular}{|c|c|c|c|c|c|c|c|c|c|c|}
\hline \multirow{2}{*}{ Description } & \multicolumn{2}{|c|}{$\begin{array}{c}\text { MAWA-GA } \\
{[3]} \\
\end{array}$} & \multicolumn{2}{|c|}{$\begin{array}{c}\text { MAWA-ACS } \\
{[7]} \\
\end{array}$} & \multicolumn{2}{|c|}{$\begin{array}{c}\text { MAWA-AS } \\
{[6]}\end{array}$} & \multicolumn{2}{|c|}{$\begin{array}{c}\text { MAWA-TLBO } \\
{[10]} \\
\end{array}$} & \multicolumn{2}{|c|}{$\begin{array}{c}\text { MAWA-ITLBO } \\
\text { (This study) }\end{array}$} \\
\hline & $\begin{array}{l}\text { Time } \\
\text { (day) }\end{array}$ & $\begin{array}{l}\text { Cost } \\
(\$)\end{array}$ & $\begin{array}{l}\text { Time } \\
\text { (day) }\end{array}$ & $\begin{array}{l}\text { Cost } \\
(\$)\end{array}$ & $\begin{array}{l}\text { Time } \\
\text { (day) }\end{array}$ & $\begin{array}{l}\text { Cost } \\
(\$)\end{array}$ & $\begin{array}{l}\text { Time } \\
\text { (day) }\end{array}$ & $\begin{array}{l}\text { Cost } \\
(\$)\end{array}$ & $\begin{array}{l}\text { Time } \\
\text { (day) }\end{array}$ & Cost (\$) \\
\hline \multirow{4}{*}{$\begin{array}{l}\text { Best results } \\
\text { obtained from the } \\
\text { models (with } \\
\text { indirect cost } \\
=\$ 1500)\end{array}$} & 100 & 287720 & 100 & 285400 & 100 & 286670 & 100 & 283420 & 100 & 283320 \\
\hline & 101 & 284020 & 101 & 282508 & 101 & 281300 & 101 & 281200 & 101 & 279820 \\
\hline & 104 & 280020 & 104 & 277200 & 104 & 277265 & 104 & 277170 & 104 & 276320 \\
\hline & 110 & 273720 & 110 & 273165 & 110 & 272265 & 110 & 273470 & 110 & 271270 \\
\hline Pop. Num & \multicolumn{2}{|c|}{50} & \multicolumn{2}{|c|}{10} & \multicolumn{2}{|c|}{50} & \multicolumn{2}{|c|}{40} & \multicolumn{2}{|r|}{40} \\
\hline Num. of iteration & \multicolumn{2}{|c|}{500} & \multicolumn{2}{|c|}{200} & \multicolumn{2}{|c|}{400} & \multicolumn{2}{|c|}{70} & \multicolumn{2}{|r|}{70} \\
\hline $\mathrm{NFE}=\mathrm{f}-$ count & \multicolumn{2}{|c|}{25000} & \multicolumn{2}{|c|}{2000} & \multicolumn{2}{|c|}{20000} & \multicolumn{2}{|c|}{5640} & \multicolumn{2}{|c|}{5640} \\
\hline
\end{tabular}

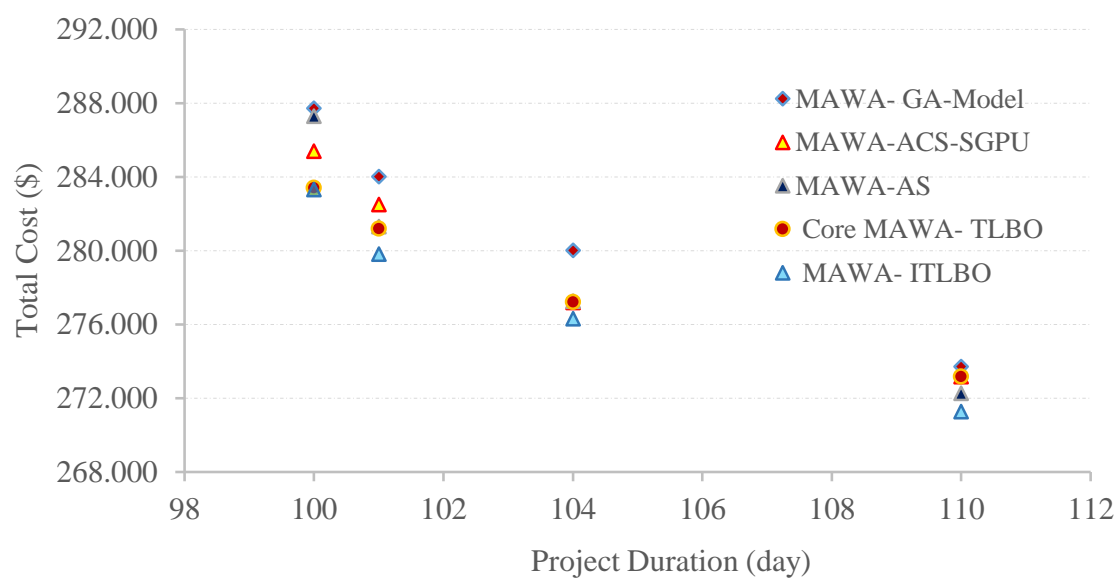

Fig. 3. Comparison of Pareto front between different algorithms for 18-activity TCT problem

It can be seen from Table 2, MAWA-ITLBO based model is executed with less size of population and number of iteration than those of the MAWA-GA and MAWA-AS models. Also, it is noticeable that the MAWA-ITLBO based model offers a more optimal cost value with the same project completion time. For example, for 100 days, the cost of solution obtained by the MAWA-ITLBO is $\$ 283320$ while MAWA-GA model cost is to $\$ 287720$. This results in a saving of $\$ 4300$ which is equivalent to $1.50 \%$ of the total cost. Although none of the existing studies achieve the optimal solutions, the proposed MAWA-ITLBO could obtain the optimal solutions for the first time in the literature. Thereby, comparing TLBO with the contemporary methods reveal that proposed TLBO is among the most suitable algorithms for providing optimal Pareto- front solutions of the more complex small-scale TCTPs.

Pareto front graphical representations of the current examined problem is given in Fig. 4. From the Fig. 4 it is clear that the global optimum solutions are achieved in the $1^{\text {th }}$ run analysis.

\subsection{Empirical example of 63-activities project}

To exhibit the performance of improved TLBO integrated with modified adaptive weighting approach on a construction project consisting more than 18 activities, a more comples project with 63 activities taken from the literature [12] is reinvestigated by MAWA-ITLBO. The activity-onnode diagram for the project is presented in Fig. 5, and time-cost optional modes are given in Table 3. The costs in Table 3 are given in US Dollars, and the durations are given in days. 


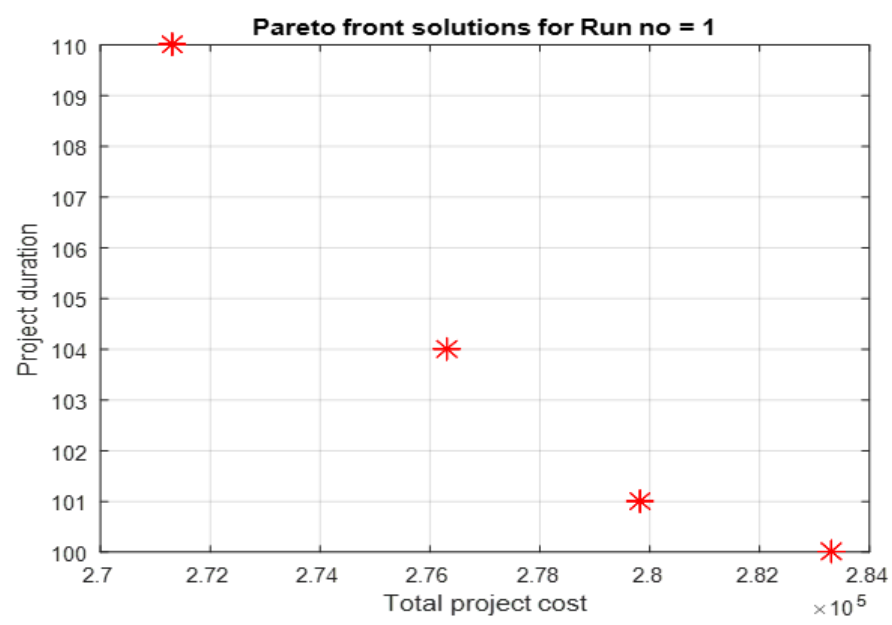

Fig. 4. Pareto optimal solutions of 18 activity problem obtained by MAWA-ITLBO

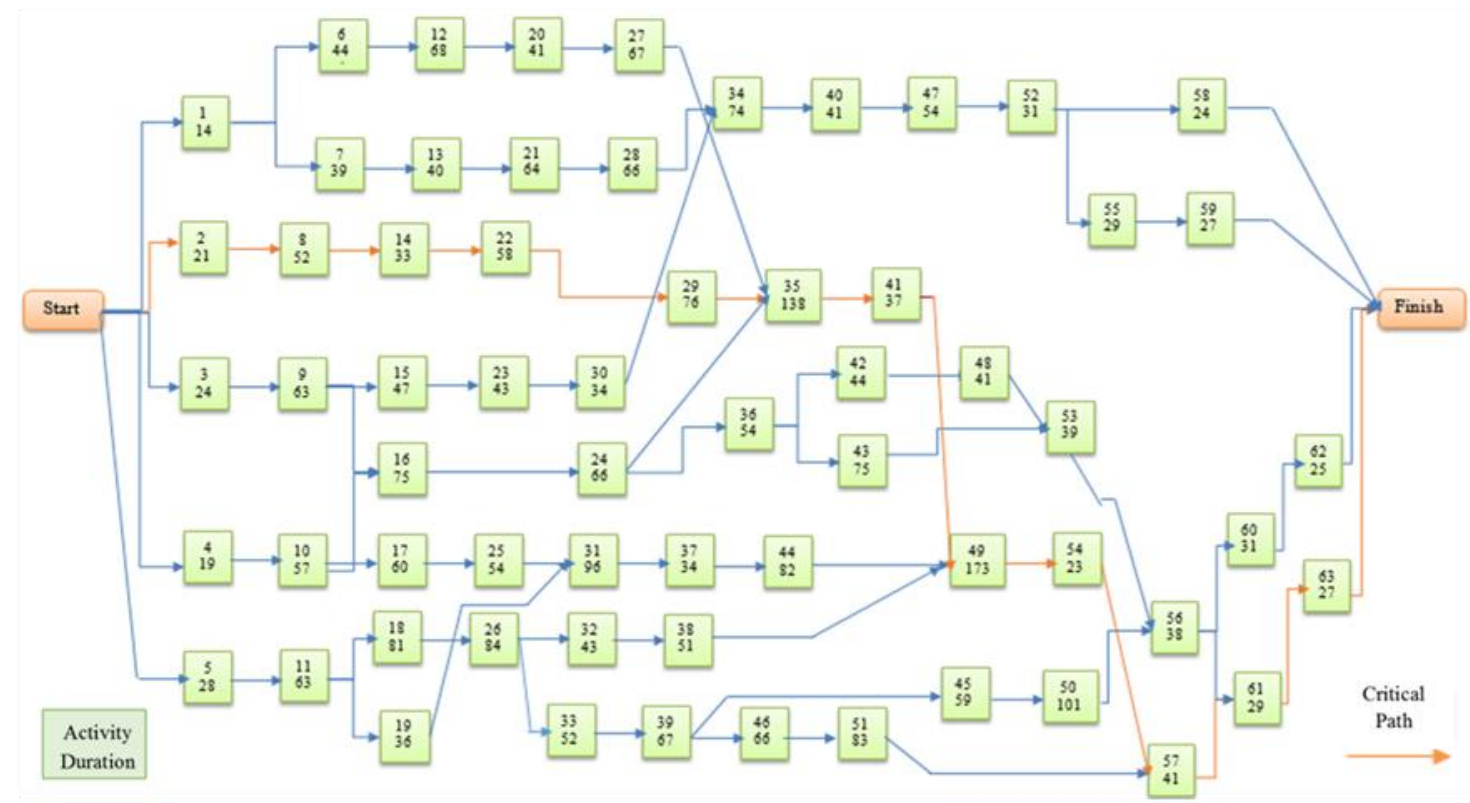

Fig. 5. Network representation of the 63 activity network

Activities of the model project have several different construction modes. For example, two activities consist of three modes, 15 activities have four modes, and 46 activities have five modes. For the project, according to given construction modes for each activity, totally $1.4 \mathrm{E}+42$ time-cost alternatives are possible. The project was investigated in two cases: in the first case (63a), the indirect cost is taken as $\$ 2300 /$ day, while it is adopted as $\$ 3500 /$ day in the second case (63b). The optimal solutions of 630days, $\$ 5,421,120$ for 63 a and 621days, $\$ 6,176,170$ for $63 \mathrm{~b}$ had been originally provided by Bettemir [12] using integer programming. Bettemir [12] utilized eight metaheuristic algorithms out of which three core algorithms and five hybrid algorithms incorporating with the non-dominating sorting approach to solve the 63 -activity TCTP problem. 
Table 3. Data for the 63-activity TCT problem

\begin{tabular}{|c|c|c|c|c|c|c|c|c|c|c|c|}
\hline \multirow{2}{*}{$\begin{array}{l}\text { Activity } \\
\text { Number }\end{array}$} & \multirow{2}{*}{$\begin{array}{c}\text { Precedent } \\
\text { Activity }\end{array}$} & \multicolumn{2}{|c|}{ Option / Mode 1} & \multicolumn{2}{|c|}{ Option / Mode 2} & \multicolumn{2}{|c|}{ Option / Mode 3} & \multicolumn{2}{|c|}{ Option / Mode 4} & \multicolumn{2}{|c|}{ Option / Mode 5} \\
\hline & & $\begin{array}{c}\text { Dur } \\
\text { (days) }\end{array}$ & $\begin{array}{l}\text { Cost } \\
(\$)\end{array}$ & $\begin{array}{c}\text { Dur } \\
\text { (days) }\end{array}$ & $\begin{array}{l}\text { Cost } \\
(\$)\end{array}$ & $\begin{array}{c}\text { Dur } \\
\text { (days) }\end{array}$ & $\begin{array}{l}\text { Cost } \\
(\$)\end{array}$ & $\begin{array}{c}\text { Dur } \\
\text { (days) }\end{array}$ & $\begin{array}{l}\text { Cost } \\
(\$)\end{array}$ & $\begin{array}{c}\text { Dur } \\
\text { (days) }\end{array}$ & $\begin{array}{l}\text { Cost } \\
(\$)\end{array}$ \\
\hline 1 & - & 14 & 3700 & 12 & 4250 & 10 & 5400 & 9 & 6250 & & \\
\hline 2 & - & 21 & 11250 & 18 & 14800 & 17 & 16200 & 15 & 19650 & & \\
\hline 3 & - & 24 & 22450 & 22 & 24900 & 19 & 27950 & 17 & 31650 & & \\
\hline 4 & - & 19 & 17800 & 17 & 19400 & 15 & 21600 & - & & & \\
\hline 5 & - & 28 & 31180 & 26 & 34200 & 23 & 38250 & 21 & 41400 & & \\
\hline 6 & 1 & 44 & 54260 & 42 & 58450 & 38 & 63225 & 35 & 68150 & & \\
\hline 7 & 1 & 39 & 47600 & 36 & 50750 & 33 & 54800 & 30 & 59750 & & \\
\hline 8 & 2 & 52 & 62140 & 47 & 69700 & 44 & 72600 & 39 & 81750 & & \\
\hline 9 & 3 & 63 & 72750 & 59 & 79450 & 55 & 86250 & 51 & 91500 & 49 & 99500 \\
\hline 10 & 4 & 57 & 66500 & 53 & 70250 & 50 & 75800 & 46 & 80750 & 41 & 86450 \\
\hline 11 & 5 & 63 & 83100 & 59 & 89450 & 55 & 97800 & 50 & 104250 & 45 & 112400 \\
\hline 12 & 6 & 68 & 75500 & 62 & 82000 & 58 & 87500 & 53 & 91800 & 49 & 96550 \\
\hline 13 & 7 & 40 & 34250 & 37 & 38500 & 33 & 43950 & 31 & 48750 & & \\
\hline 14 & 8 & 33 & 52750 & 30 & 58450 & 27 & 63400 & 25 & 66250 & & \\
\hline 15 & 9 & 47 & 38140 & 40 & 41500 & 35 & 47650 & 32 & 54100 & & \\
\hline 16 & 9,10 & 75 & 94600 & 70 & 101250 & 66 & 112750 & 61 & 124500 & 57 & 132850 \\
\hline 17 & 10 & 60 & 78450 & 55 & 84500 & 49 & 91250 & 47 & 94640 & & \\
\hline 18 & 10,11 & 81 & 127150 & 73 & 143250 & 66 & 154600 & 47 & 161900 & & \\
\hline 19 & 11 & 36 & 82500 & 34 & 94800 & 30 & 101700 & - & & & \\
\hline 20 & 12 & 41 & 48350 & 37 & 53250 & 34 & 59450 & 32 & 66800 & & \\
\hline 21 & 13 & 64 & 85250 & 60 & 92600 & 57 & 99800 & 53 & 107500 & 49 & 113750 \\
\hline 22 & 14 & 58 & 74250 & 53 & 79100 & 50 & 86700 & 47 & 91500 & 42 & 97400 \\
\hline 23 & 15 & 43 & 66450 & 41 & 69800 & 37 & 75800 & 33 & 81400 & 30 & 88450 \\
\hline 24 & 16 & 66 & 72500 & 62 & 78500 & 58 & 83700 & 53 & 89350 & 49 & 96400 \\
\hline 25 & 17 & 54 & 66650 & 50 & 70100 & 47 & 74800 & 43 & 79500 & 40 & 86800 \\
\hline 26 & 18 & 84 & 93500 & 79 & 102500 & 73 & 111250 & 68 & 119750 & 62 & 128500 \\
\hline 27 & 20 & 67 & 78500 & 60 & 86450 & 57 & 89100 & 56 & 91500 & 53 & 94750 \\
\hline 28 & 21 & 66 & 85000 & 63 & 89750 & 60 & 92500 & 58 & 96800 & 54 & 100500 \\
\hline 29 & 22 & 76 & 92700 & 71 & 98500 & 67 & 104600 & 64 & 109900 & 60 & 115600 \\
\hline 30 & 23 & 34 & 27500 & 32 & 29800 & 29 & 31750 & 27 & 33800 & 26 & 36200 \\
\hline 31 & 19,25 & 96 & 145000 & 89 & 154800 & 83 & 168650 & 77 & 179500 & 72 & 189100 \\
\hline 32 & 26 & 43 & 43150 & 40 & 48300 & 37 & 51450 & 35 & 54600 & 33 & 61450 \\
\hline 33 & 26 & 52 & 61250 & 49 & 64350 & 44 & 68750 & 41 & 74500 & 38 & 79500 \\
\hline 34 & 28,30 & 74 & 89250 & 71 & 93800 & 66 & 99750 & 62 & 105100 & 57 & 114250 \\
\hline 35 & $24,27,29$ & 138 & 183000 & 126 & 201500 & 115 & 238000 & 103 & 283750 & 98 & 297500 \\
\hline 36 & 24 & 54 & 47500 & 49 & 50750 & 42 & 56800 & 38 & 62750 & 33 & 68250 \\
\hline 37 & 31 & 34 & 22500 & 32 & 24100 & 29 & 26750 & 27 & 29800 & 24 & 31600 \\
\hline 38 & 32 & 51 & 61250 & 47 & 65800 & 44 & 71250 & 41 & 76500 & 38 & 80400 \\
\hline 39 & 33 & 67 & 81150 & 61 & 87600 & 57 & 92100 & 52 & 97450 & 49 & 102800 \\
\hline 40 & 34 & 41 & 45250 & 39 & 48400 & 36 & 51200 & 33 & 54700 & 31 & 58200 \\
\hline 41 & 35 & 37 & 17500 & 31 & 21200 & 27 & 26850 & 23 & 32300 & & \\
\hline 42 & 36 & 44 & 36400 & 41 & 39750 & 38 & 42800 & 32 & 48300 & 30 & 50250 \\
\hline
\end{tabular}


Table 3. Cont'd

\begin{tabular}{lccccccccccc}
43 & 36 & 75 & 66800 & 69 & 71200 & 63 & 76400 & 59 & 81300 & 54 & 86200 \\
44 & 37 & 82 & 102750 & 76 & 109500 & 70 & 127000 & 66 & 136800 & 63 & 146000 \\
45 & 39 & 59 & 847500 & 55 & 91400 & 51 & 101300 & 47 & 126500 & 43 & 142750 \\
46 & 39 & 66 & 94250 & 63 & 99500 & 59 & 108250 & 55 & 118500 & 50 & 136000 \\
47 & 40 & 54 & 73500 & 51 & 78500 & 47 & 83600 & 44 & 88700 & 41 & 93400 \\
48 & 42 & 41 & 36750 & 39 & 39800 & 37 & 43800 & 34 & 48500 & 31 & 53950 \\
49 & $38,41,44$ & 173 & 267500 & 159 & 289700 & 147 & 312000 & 138 & 352500 & 121 & 397750 \\
50 & 45 & 101 & 47800 & 74 & 61300 & 63 & 76800 & 49 & 91500 & & \\
51 & 46 & 83 & 84600 & 77 & 93650 & 72 & 98500 & 65 & 104600 & 61 & 113200 \\
52 & 47 & 31 & 23150 & 28 & 27600 & 26 & 29800 & 24 & 32750 & 21 & 35200 \\
53 & 43,48 & 39 & 31500 & 36 & 34250 & 33 & 37800 & 29 & 41250 & 26 & 44600 \\
54 & 49 & 23 & 16500 & 22 & 17800 & 21 & 19750 & 20 & 21200 & 18 & 24300 \\
55 & 52,53 & 29 & 23400 & 27 & 25250 & 26 & 26900 & 24 & 29400 & 22 & 32500 \\
56 & 50,53 & 38 & 41250 & 35 & 44650 & 33 & 47800 & 31 & 51400 & 29 & 55450 \\
57 & 51,54 & 41 & 37800 & 38 & 41250 & 35 & 45600 & 32 & 49750 & 30 & 53400 \\
58 & 52 & 24 & 12500 & 22 & 13600 & 20 & 15250 & 18 & 16800 & 16 & 19450 \\
59 & 55 & 27 & 34600 & 24 & 37500 & 22 & 41250 & 19 & 46750 & 17 & 50750 \\
60 & 56 & 31 & 28500 & 29 & 30500 & 27 & 33250 & 25 & 38000 & 21 & 43800 \\
61 & 56,57 & 29 & 22500 & 27 & 24750 & 25 & 27250 & 22 & 29800 & 20 & 33500 \\
62 & 60 & 25 & 38750 & 23 & 41200 & 21 & 44750 & 19 & 49800 & 17 & 51100 \\
63 & 61 & 27 & 9500 & 26 & 9700 & 25 & 10100 & 24 & 10800 & 22 & 12700 \\
\hline
\end{tabular}

The MAWA-ITLBO searched $48120(=120 \mathrm{x}$ $200 \times 2+120$ ) possible different schedules, only searching a negligible portion of the solution space [48120/1.4E+42] could generate the Pareto front solutions where number of population and iteration are 120 and 200, respectively.

Therefore, number of function evaluations is 48120 , and the APD values are \%1.998 and \%0.557 respectively. It can be stated that the proposed MAWA-ITLBO model requires less the size of population and number of iteration than those of the basic MAWA-TLBO and the other models.

Considering the solutions obtained it can be concluded that the proposed MAWA-ITLBO model in this study produces satisfactory results for both $63 \mathrm{a}$ and $63 \mathrm{~b}$ cases. Depending up on this result, and referring on Tables 4-5, it can be stated that MAWA-ITLBO could achieve better solutions than MAWA-TLBO, MAWA-GA [13] and MAWA-PSO [13] for both 63a and 63b cases. MAWA-ITLBO model produces alternatives Pareto front solutions for the first time in the literature.
Table 6 illustrates Pareto front results of ten consecutive experimental runs with corresponding average percent deviations (\%APD) from the optima.

\section{Conclusion}

In this paper, a multiobjective optimization model called as MAWA-ITLBO has been proposed to optimize the total project duration and total cost simultaneously for construction project. The largest model project practiced using metaheuristic algorithms integrated with MAWA approach was the project with 18 -activities. None of the previous studies could achieve the global optimal solution with modified adaptive weight approach. However, in the current study, the exploration capacity of the algorithm has improved by means of the multiteacher and adaptive teaching factor strategies and could obtain the global optimal solutions for the first time in the literature. From the results, it is clear that the applied MAWA-ITLBO algorithm is proficient of finding global optimum solutions for the small e.g. 18 -activity problems. 
Table 4. Analysis results of 63a-Activity project for the Case 1 (daily indirect cost of \$2300)

\begin{tabular}{|c|c|c|c|c|c|c|c|c|}
\hline \multirow[t]{2}{*}{ Search no } & \multicolumn{2}{|c|}{$\begin{array}{c}\text { MAWA-GA } \\
{[13]}\end{array}$} & \multicolumn{2}{|c|}{$\begin{array}{c}\text { MAWA-PSO } \\
{[13]}\end{array}$} & \multicolumn{2}{|c|}{$\begin{array}{c}\text { MAWA-TLBO } \\
{[10]}\end{array}$} & \multicolumn{2}{|c|}{$\begin{array}{l}\text { MAWA-ITLBO } \\
\text { (This study) }\end{array}$} \\
\hline & Dur & Cost & Dur & Cost & Dur & Cost & Dur & Cost \\
\hline 1 & 519 & 5825480 & 602 & 5920580 & 629 & 5613820 & 629 & 5587780 \\
\hline 2 & 528 & 5687020 & 620 & 5904125 & 614 & 5644640 & 614 & 5491920 \\
\hline 3 & 522 & 5725380 & 594 & 5701200 & 630 & 5600190 & 612 & 5499090 \\
\hline 4 & 523 & 5765800 & 606 & 5837980 & 616 & 5623260 & 616 & 5512835 \\
\hline 5 & 524 & 5827200 & 630 & 5994490 & 630 & 5642405 & 615 & 5512435 \\
\hline 6 & 516 & 6052120 & 617 & 5925980 & 637 & 5637290 & 611 & 5515920 \\
\hline 7 & 517 & 5722600 & 614 & 5751470 & 639 & 5503940 & 602 & 5480820 \\
\hline 8 & 519 & 5872000 & 627 & 5934330 & 630 & 5696820 & 631 & 5635510 \\
\hline 9 & 519 & 5818480 & 610 & 5924365 & 627 & 5588485 & 626 & 5529170 \\
\hline 10 & 522 & 5716980 & 581 & 5858295 & 632 & 5625310 & 610 & 5529120 \\
\hline Populations in an iteration & \multicolumn{2}{|c|}{500} & \multicolumn{2}{|c|}{500} & \multicolumn{2}{|c|}{180} & \multicolumn{2}{|c|}{120} \\
\hline $\begin{array}{c}\text { Number of iterations to get } \\
\text { the solutions }\end{array}$ & \multicolumn{2}{|c|}{500} & \multicolumn{2}{|c|}{500} & \multicolumn{2}{|c|}{450} & \multicolumn{2}{|c|}{200} \\
\hline $\begin{array}{c}\text { Number of function } \\
\text { evaluation }\end{array}$ & \multicolumn{2}{|c|}{250000} & \multicolumn{2}{|c|}{250000} & \multicolumn{2}{|c|}{162180} & \multicolumn{2}{|c|}{48120} \\
\hline
\end{tabular}

Table 5. Analysis results of 63b-Activity project for the Case 2 (daily indirect cost of $\$ 3500$ )

\begin{tabular}{|c|c|c|c|c|c|c|c|c|}
\hline \multirow[t]{2}{*}{ Search no } & \multicolumn{2}{|c|}{$\begin{array}{c}\text { MAWA-GA } \\
\text { [13] }\end{array}$} & \multicolumn{2}{|c|}{$\begin{array}{c}\text { MAWA-PSO } \\
\text { [13] }\end{array}$} & \multicolumn{2}{|c|}{$\begin{array}{c}\text { MAWA-TLBO } \\
{[10]} \\
\end{array}$} & \multicolumn{2}{|c|}{$\begin{array}{c}\text { MAWA-ITLBO } \\
\text { (This study) }\end{array}$} \\
\hline & Dur & Cost & Dur & Cost & Dur & Cost & Dur & Cost \\
\hline 1 & 521 & 6350810 & 615 & 6951145 & 630 & 6291540 & 630 & 6278020 \\
\hline 2 & 517 & 6345370 & 614 & 6668150 & 628 & 6264970 & 628 & 6198070 \\
\hline 3 & 522 & 6560040 & 611 & 6931330 & 630 & 6280170 & 630 & 6198570 \\
\hline 4 & 513 & 6435790 & 620 & 6572210 & 637 & 6262570 & 637 & 6232860 \\
\hline 5 & 529 & 6471800 & 619 & 6441665 & 625 & 6292850 & 625 & 6191230 \\
\hline 6 & 524 & 6538310 & 619 & 6549420 & 613 & 6261820 & 633 & 6210620 \\
\hline 7 & 525 & 6322020 & 628 & 6621405 & 624 & 6289790 & 627 & 6188140 \\
\hline 8 & 522 & 6443780 & 608 & 6428310 & 622 & 6280170 & 622 & 6191940 \\
\hline 9 & 521 & 6410470 & 617 & 6582925 & 636 & 6280750 & 636 & 6201570 \\
\hline 10 & 519 & 6397730 & 622 & 6783495 & 634 & 6263980 & 634 & 6215160 \\
\hline $\begin{array}{c}\text { Populations in an } \\
\text { iteration }\end{array}$ & \multicolumn{2}{|c|}{500} & \multicolumn{2}{|c|}{500} & \multicolumn{2}{|c|}{180} & \multicolumn{2}{|c|}{120} \\
\hline $\begin{array}{l}\text { Number of iterations } \\
\text { to get the solutions }\end{array}$ & \multicolumn{2}{|c|}{500} & \multicolumn{2}{|c|}{500} & \multicolumn{2}{|c|}{450} & \multicolumn{2}{|c|}{200} \\
\hline $\begin{array}{c}\text { Number of function } \\
\text { evaluation }\end{array}$ & \multicolumn{2}{|c|}{250000} & \multicolumn{2}{|c|}{250000} & \multicolumn{2}{|c|}{162180} & \multicolumn{2}{|c|}{48120} \\
\hline
\end{tabular}

Table 6. Average deviations from the optima for problems 63a and 63b.

\begin{tabular}{cccccc}
\hline \multirow{2}{*}{ Algorithms } & $63 \mathrm{a}$ & & \multicolumn{2}{c}{$63 \mathrm{~b}$} & APD (\%) \\
\cline { 2 - 3 } & No of Runs & & No of Runs & \\
\hline MAWA-GA [13] & 10 & 7.013 & 10 & 4.071 \\
MAWA-PSO [13] & 10 & 8.378 & 10 & 7.721 \\
MAWA-TLBO [10] & 10 & 3.528 & 10 & 1.630 \\
MAWA-ITLBO (This paper) & 10 & 1.998 & 10 & 0.557 \\
\hline
\end{tabular}




\section{References}

[1] Deb K., Multiobjective Optimization Using Evolutionary Algorithms. New York: John Wiley and Sons Ltd., England (2001).

[2] Gen M., Cheng R. Genetic Algorithms and Engineering Optimization. Wiley-International science, New York (2000).

[3] Zheng D., Ng S., Kumaraswamy M. Applying Pareto Ranking and Niche Formation to Genetic Algorithm-Based Multiobjective Time-Cost Optimization. Journal of Construction Engineering and Management 131(1) (2005) 81-91.

[4] Feng C-W., Liu L., Burns S. Stochastic Construction Time Cost Trade-Off Analysis. Journal of Computing in Civil Engineering 14(2) (1997) 117-126.

[5] Ng S. T., Zhang Y. S. Optimizing Construction Time and Cost Using Ant Colony Optimization Approach. Journal of Construction Engineering and Management ASCE 134(9) (2008) 721-728.

[6] Afshar A., Kaveh. A., Kasaeian A., Shoghli O.R., Modified Adaptive Weighting Method for TimeCost Trade-off Problem based on Ant Colony Optimization. 3rd National Congress on Civil Engineering (2008).

[7] Zhang Y., S Ng. An Ant Colony System Based Decision Support System for Construction TimeCost Optimization. Journal of Civil Engineering and Management 18(4) (2012) 580-589.

[8] Rao R.V., Savsani V.J., Vakharia D.P., TeachingLearning-Based Optimization: A Novel Method for Constrained Mechanical Design Optimization Problems. Computation Aided Design 43(3) (2011) 303-315

[9] Rao R. V., Patel V. An Improved TeachingLearning-Based Optimization Algorithm for Solving Unconstrained Optimization Problems. Scientia Iranica 20(3) (2013) 710-720

[10] Eirgash M. A. Pareto-Front Performance of Multiobjective Teaching Learning Based Optimization Algorithm on Time-Cost Trade-Off Optimization Problems. Master of Science Thesis, Karadeniz Technical University Turkey (2018).

[11] Zheng D.X.M., Ng S.T., Kumaraswamy M. Applying A Genetic Algorithm-Based Multiobjective Approach for Time-Cost Optimization. Journal of Construction Engineering and Management 130(2) (2004) 168 - 176.

[12] Bettemir Ö. H. Optimization of Time-CostResource Trade-off Problems in Project Scheduling
Using Meta-heuristic Algorithms. Doctoral dissertation, Middle East Technical University, Turkey (2009).

[13] Toğan V., Eirgash M. A. Time-Cost Trade-off Optimization of Construction Projects Using Teaching Learning Based Optimization. KSCE Journal of Civil Engineering, (2018-Accepted). 